\title{
Revisão sobre cromatografia líquida acoplada à espectrometria de massas aplicada à análise toxicológica de alimentos
}

\author{
Review on liquid chromatography coupled with mass spectrometry applied to food toxicological \\ analysis
}

Revisión de la cromatografía líquida acoplado con la espectrometría de masas aplicada al análisis toxicológico de los alimentos

Recebido: 24/04/2021 | Revisado: 29/04/2021 | Aceito: 29/04/2021 | Publicado: 14/05/2021

Dilceu Silveira Tolentino Júnior ORCID: https://orcid.org/0000-0003-2435-7576 Universidade Federal dos Vales do Jequitinhonha e Mucuri, Brasil E-mail: dilceujunior@bol.com.br

Sandra Neres Santos

ORCID: https://orcid.org/0000-0002-2542-2723

Universidade Federal dos Vales do Jequitinhonha e Mucuri, Brasil E-mail: sandraneres2008@hotmail.com

Arlanjo Bispo de Sousa Marques ORCID: https://orcid.org/0000-0002-1710-3298 Universidade Federal dos Vales do Jequitinhonha e Mucuri, Brasil E-mail: arlanjomarques@ hotmail.com

Kleise Pinheiro Farias

ORCID: https://orcid.org/0000-0001-8418-1643 Secretaria Municipal de Saúde de Crisólita, Brasil E-mail: saudecris@yahoo.com.br

André Barbosa Souza

ORCID: https://orcid.org/0000-0001-7805-949X Secretaria Municipal de Saúde de Águas Formosas, Brasil

E-mail: aps.fronteiradosvales@gmail.com

Gracielly Nascimento Lima

ORCID: https://orcid.org/0000-0001-6939-1626 Hospital São Vicente de Paulo, Brasil

E-mail: gatyaf@outlook.com

Jairo Lisboa Rodrigues

ORCID: https://orcid.org/0000-0001-6088-5232 Universidade Federal dos Vales do Jequitinhonha e Mucuri, Brasil E-mail: jairo.rodrigues@ufvjm.edu.br

\begin{abstract}
Resumo
A cromatografia líquida de alta eficiência (HPLC) acoplada à espectrometria de massas (EM) constitui-se como uma das mais importantes técnicas analíticas utilizadas na determinação de compostos não voláteis ou instáveis termicamente. A combinação de ambas une a excelência da separação do analito de interesse na matriz através da técnica da cromatografia líquida de alto desempenho, juntamente com a técnica da espectrometria de massas que confirma a identificação química. Dentre as alternativas disponíveis, a espectrometria de massas é a que melhor fornece as informações estruturais necessárias. $\mathrm{O}$ acoplamento entre estas duas técnicas dá origem a uma ferramenta analítica robusta, versátil e de grande potencial na análise qualitativa e quantitativa em toxicologia de alimentos. $\mathrm{O}$ presente artigo apresenta uma revisão de literatura que tem o objetivo de apresentar os fundamentos da aplicação do acoplamento da Cromatografia Líquida e Espectrometria de Massas na área de análise de alimentos.
\end{abstract}

Palavras-chave: Cromatografia líquida; HPLC; Espectrometria de massas; CL/EM; Toxicologia; Alimentos.

\begin{abstract}
High performance liquid chromatography (HPLC) coupled with mass spectrometry (MS) is one of the most important analytical techniques used in the determination of non-volatile or thermally unstable compounds. The combination of both unites the excellence of the separation of the analyte of interest in the matrix through the high performance liquid chromatography technique, together with the mass spectrometry technique that confirms the chemical identification. Among the available alternatives, mass spectrometry is the one that best provides the necessary structural information. The coupling between these two techniques gives rise to a robust, versatile and great potential analytical tool in the
\end{abstract}


qualitative and quantitative analysis in food toxicology. This article presents a literature review that aims to present the fundamentals of the application of the coupling of Liquid Chromatography and Mass Spectrometry in the area of food analysis.

Keywords: Liquid chromatography; HPLC; Mass spectrometry; LC/MS; Toxicology; Foods.

\section{Resumen}

La cromatografía líquida de alta resolución (HPLC) junto con la espectrometría de masas (EM) es una de las técnicas analíticas más importantes utilizadas en la determinación de compuestos no volátiles o térmicamente inestables. La combinación de ambos une la excelencia de la separación del analito de interés en la matriz mediante la técnica de cromatografía líquida de alta resolución, junto con la técnica de espectrometría de masas que confirma la identificación química. Entre las alternativas disponibles, la espectrometría de masas es la que mejor aporta la información estructural necesaria. El acoplamiento entre estas dos técnicas da lugar a una herramienta analítica robusta, versátil y de gran potencial en el análisis cualitativo y cuantitativo en toxicología alimentaria. Este artículo presenta una revisión de la literatura que tiene como objetivo presentar los fundamentos de la aplicación del acoplamiento de la cromatografía líquida y la espectrometría de masas en el área del análisis de alimentos.

Palabras clave: Cromatografía líquida; HPLC; Espectrometría de masas; CL/EM; Toxicología; Alimentos.

\section{Introdução}

A cromatografia líquida de alta eficiência (HPLC) é uma técnica responsável por grandes avanços na área cromatográfica. A HPLC utiliza suporte com partículas diminutas responsáveis pela alta eficiência, sendo um método adequado para separação de espécies iônicas e macromoléculas (Degani et al.,1998). Assim a utilização da HPLC necessita de um cromatógrafo composto de bomba, coluna cromatográfica, detector e registrador (Degani et al., 1998; Peres, 2002).

A cromatografia pode ser combinada a diferentes sistemas de detecção, tratando-se de uma das técnicas analíticas mais utilizadas e de melhor desempenho. O acoplamento de um cromatógrafo com o espectrômetro de massas combina as vantagens da cromatografia (alta seletividade e eficiência de separação) com as vantagens da espectrometria de massas, obtenção de informação estrutural, massa molar e aumento adicional da seletividade (Vékey, 2001). Para que o acoplamento seja possível, idealmente, é necessário que as características de cada instrumento não sejam afetadas pela sua conexão, assim como não devem ocorrer modificações químicas não controladas do analito e perda de amostra durante a sua passagem do cromatógrafo para o espectrômetro de massas (Ardrey, 2003).

Diante do acoplamento da cromatografia a técnicas espectrais várias siglas surgiram, sendo as mais utilizadas listadas a seguir: cromatografia líquida de alta eficiência acoplada ao espectrômetro de massas (HPLC-MS), cromatografia líquida de alta eficiência acoplada à espectroscopia de infravermelha (HPLC-IR), cromatografia gasosa acoplada à espectrometria de massas (GC-MS), entre inúmeras outras que surgem a cada método publicado (PateL et al., 2010; Chinchole et al., 2012).

A técnica cromatográfica pode ser utilizada para dosar compostos em alimentos (Gilbert-López et al. 2012; Xu et al., 2012), no monitoramento de componentes tóxicos no meio ambiente (Marriott et al., 2003) ou mesmo na indústria petroquímica (Mühlen et al., 2006). Dessa forma é difícil definir em qual área dentro dessa ciência que mais se utiliza das técnicas cromatográficas.

Na medicina veterinária a cromatografia tem a possibilidade de ser utilizada em diversos meios, como em estudos de farmacocinética (Amorim et al., 2008), para monitorar resíduos de drogas em produtos de origem animal (Cardoso et al., 1999; Feltrin et al., 2007; ANVISA, 2009), na toxicologia (Kaiser et al., 2010; Oliveira-Filho et al., 2010; Lee et al., 2012), entre outros.

As aplicações das técnicas cromatográficas cresceram intensamente nos últimos 50 anos; isto se deve não somente ao desenvolvimento de novos tipos de técnicas de preparação, separação e detecção, mas também pela necessidade crescente de técnicas mais precisas e sensíveis para a caracterização e quantificação de pesticidas de interesse em matrizes complexas, tais como alimentos, águas, ar, solo e fluidos biológicos (Sanches et al., 2003). 
Todos os consumidores de uma cadeia alimentar podem ser contaminados por meio de grãos infectados, ração, leite, ovos e carnes contendo micotoxinas. Torna-se crucial, portanto, o controle da contaminação nas diferentes etapas de produção, armazenamento e processamento de alimentos, o que requer a utilização de técnicas que visam monitorar a dispersão das micotoxinas (Pitt \& Koching; Calvo, 2005).

\section{Metodologia}

A estratégia metodológica definida no estudo foi a revisão bibliográfica, conforme descrita por Pereira et al. (2018), com uma pesquisa exploratória elaborada a partir de artigos científicos previamente publicados. Para selecionar os artigos foram utilizados os bancos de dados: Scopus, Scielo.br e Pubmed, usando os principais termos de busca: cromatografia líquida, HPLC, espectrometria de massas, MS, toxicologia, alimentos. Foram utilizados os termos de busca nos idiomas inglês e português para possibilitar uma pesquisa abrangente sobre a temática escolhida.

No total foram recrutados em torno de 60 trabalhos para a revisão geral, porém artigos que após leitura não se referiram ao objetivo principal da presente pesquisa foram excluídos. No total, 20 estudos foram selecionados para a discussão dos fundamentos da cromatografia líquida de alta performance $(n=10)$, e da espectrometria de massas $(n=10)$, assim como o acoplamento de ambas as tecnologias para demonstrar tais aplicabilidades na área de análise de alimentos. Os trabalhos utilizados tiverem seus dados publicados entre os anos de 2008 a 2015.

\section{Desenvolvimento}

\subsection{A cromatografia para identificação de substâncias nocivas em alimentos}

A ausência de boas práticas veterinárias na criação de animais de produção pode acarretar o uso indiscriminado de medicamentos sem a preocupação do resíduo destes no produto final, o que pode significar risco à saúde pública (ANVISA, 2006; 2009). Esses riscos podem ser traduzidos pela ocorrência de resistência bacteriana (ANVISA, 2006; 2009), reações alérgicas que podem ocasionar choque anafilático (ANVISA, 2009), entre outros. Assim, a utilização da cromatografia tem auxiliado na detecção destas substâncias em produtos de origem animal (Cardoso et al., 1999; Feltrin et al., 2007; ANVISA, 2009).

Os resíduos de antibióticos são quaisquer substâncias, mistura de antibióticos, derivados específicos, metabólitos ou produtos de reação dos antibióticos presentes nos alimentos para o homem ou para os animais, que possam ser considerados de importância toxicológica (Manjarrez et al., 2012). No entanto, há relativamente poucos métodos analíticos capazes de medir as concentrações residuais de muitos antibióticos. A baixa solubilidade de alguns antibióticos em solventes orgânicos torna difícil o desenvolvimento de técnicas para extrair seus resíduos de matrizes biológicas. Outros antibióticos são demasiadamente instáveis termicamente ou insuficientemente voláteis para serem processados por CG ou CG-MS. Dessa forma, várias técnicas de detecção de resíduos de antibióticos foram desenvolvidas utilizando HPLC. Apesar disso, muitas vezes somente a HPLC não é suficiente para detecção de traços desses medicamentos, sendo necessário associar a espectrometria de massas (Kennedy et al., 1998). Assim, muitos pesquisadores têm publicado trabalhos que descrevem a detecção de antibióticos por técnicas cromatográficas (Feltrin et al., 2007; Pietrón et al., 2011; Manjarrez et al., 2012).

Em um estudo que trabalhou com resíduos de sulfadimetoxina, os pesquisadores detectaram resíduos do referido medicamento por HPLC. No estudo, as amostras de leite foram enriquecidas com solução padrão de sulfadimetoxina. Posteriormente, foi realizada a extração com cartucho comercial específico. Após a extração, as amostras foram submetidas a um cromatógrafo líquido de alta eficiência com detector ultravioleta (UV). Por meio dessa técnica foi possível recuperar entre 76 a 90\% do padrão comercial adicionado à amostra (Feltrin et al., 2007). 
Outro grupo de antibióticos muito utilizado em animais de produção são as penicilinas. Estima-se que 3 a $10 \%$ da população sejam susceptíveis a reações alérgicas quando expostas a alimentos contendo esse grupo de medicamentos (ANVISA, 2009). Deste modo, a cromatografia tem sido utilizada como ferramenta de apoio na detecção de penicilinas em produtos de origem animal. Pesquisadores utilizaram amostras de leite e carne enriquecidas com penicilina G, oxacilina e cloxacilina. As amostras foram extraídas e posteriormente submetidas à HPLC com detector UV. Os autores puderam concluir que os métodos para determinação simultânea de penicilinas no leite e carne apresentaram resultados favoráveis (Kukusamude et al., 2012).

Além dos antibióticos, outras drogas podem ser utilizadas no tratamento dos animais de produção, como os antiinflamatórios e anti-helmínticos, no entanto elas também podem deixar resíduos nos produtos finais (Souza et al., 2003; Lobato et al., 2006; Gentili et al., 2012). Recentemente foi utilizada cromatografia líquida acoplada ao espectrômetro de massas, o que permitiu a detecção simultânea de 15 diferentes agentes antiinflamatórios não esteroidais, no leite e músculo de bovinos (Gentili et al., 2012).

Já em relação aos antihelmínticos, pesquisadores utilizaram a HPLC ligada a detector de fluorescência para dosar resíduos de ivermectinas no fígado de bovinos. Os pesquisadores utilizaram fígado livre de resíduos dessas drogas, separaram as amostras e posteriormente enriqueceram-nas com abamectina, doramectina e ivermectina. Após a extração das amostras, o extrato derivativo foi analisado por HPLC-FI. A taxa de recuperação para as amostras adicionadas de solução padrão foi de 101,$1 ; 101,0$ e 96,7\%, com coeficientes de variação de 11,2; 9,2 e 12,5\% para abamectina, doramectina e ivermectina, respectivamente (Souza et al., 2003).

Em outro estudo pesquisadores colheram 168 amostras de leite que estavam sendo comercializadas em supermercados de Campinas - SP e da região metropolitana do Rio de Janeiro. Essas amostras foram analisadas por HPLC com detector por fluorescência, e foi detectado que 17,8\% das amostras eram positivas para ivermectinas, no entanto as amostras não continham resíduos em quantidade superior aos estabelecidos pelo Ministério da Agricultura Pecuária e Abastecimento (Lobato et al., 2006).

Outros agentes tóxicos comuns de alimentos de origem animal são as micotoxinas. Essas toxinas podem ser transmitidas para os alimentos após o consumo de rações contaminadas. Devido a isso pesquisadores têm utilizado de métodos cromatográficos para detecção desses contaminantes (Netto et al., 2002).

Em um estudo realizado com 75 amostras de queijo foram detectadas, por meio de HPLC usando detector de fluorescência, que 56 (74,7\%) estavam contaminados com aflotoxina M1 (Prado et al., 2000). Em outra pesquisa foi realizado teste para detectar as aflotoxinas no leite de bovinos. A HPLC foi utilizada e puderam constatar que 19 (52,8\%) amostras estavam contaminadas, mas os níveis da aflotoxina M1 estavam dentro dos padrões tolerados pela legislação brasileira (Pereira et al., 2005).

Por fim, há drogas que por vezes são utilizadas, mas sem autorização para seu emprego no Brasil. Dentre elas estão os esteroides anabolizantes, os quais também podem deixar resíduos nos produtos de origem animal. Diante disto, métodos cromatográficos são importantes ferramentas para a análise dessas drogas (Duarte et al., 2002). Com auxílio da cromatografia líquida de ultra eficiência associada a espectrofotometria de massa pesquisadores puderam desenvolver metodologia para detectar simultaneamente 34 anabolizantes esteroides em músculo bovinos. No estudo, amostras de tecido muscular bovino, livres destas drogas foram enriquecidas com padrões das mesmas, posteriormente as amostras foram extraídas e submetidas a U-HPLC-MS/MS, quando os esteroides anabolizantes foram identificados (Vanhaecke et al., 2012). 


\subsection{A cromatografia para identificaçâo de micotoxinas em cereais e leguminosas}

As micotoxinas são metabólicos secundários tóxicos produzidos por fungos, que se desenvolvem naturalmente em alimentos, razão pela qual é importante o desenvolvimento de técnicas de quimioavaliação, constituindo-se da identificação e quantificação por cromatografia em camada delgada (CCD) e cromatografia líquida de alta resolução (HPLC). Estes métodos apresentam alta eficiência e segurança diagnóstica, sendo, portanto, os mais recomendados (Organisación Mundial de la Salud, 1983; Sabino, 1988).

Alguns produtos alimentícios como amendoim, milho, feijão, arroz, trigo, entre outros, podem conter aflatoxinas desenvolvidas de forma natural. Dentre eles, o amendoim é o mais sensível, sendo que a invasão de microorganismos neste cereal pode ocorrer no solo, durante o processo de formação de sementes, na colheita, nas fases de secagem, beneficiamento e armazenamento (Bruno, 2000).

Todos os cereais, sem exceção, devem ser alvos de controle, pois podem estar contaminados. O arroz e o feijão, entretanto, exigem um olhar mais atento, por se tratar de alimentos que diariamente estão na mesa do brasileiro. Estudos anteriores demonstraram que o arroz não é um dos alimentos mais suscetíveis às aflatoxinas, mas pode contê-las (Nunes et al., 2003).

Dentre as micotoxinas que ocorrem com maior frequiência em alimentos tem-se: a) as aflatoxinas que podem ser produzidas por fungos como Aspergillus flavus, A. parasiticus e A. nominus, e dentre os vários tipos destacam-se B1, B2, G1 e G2 (Yu et al., 2005; Bok et al., 2004); b) as fumonisinas e os tricotecenos, que incluem deoxinivalenol e zearalenona, são produzidos por fungos do gênero Fusarium (Pozzi et al., 2002); c) a patulina produzida por diversas espécies de fungos sendo que o mais citado é do gênero Penicillium (Machinski Jr \& Mídio, 1995); d) as ocratoxinas produzidas por diversas espécies dos gêneros Aspergillus e Penicillium (Leeson et al., 1995).

A contaminação ocasionada por micotoxinas, em geral, não pode ser visualizada a olho nu, sendo assim, os produtos uma vez contaminados seguem para comercialização, com a presença de compostos capazes de provocar enfermidades e muitas vezes levar à morte. Tal mecanismo resulta em uma exposição contínua a pequenas doses de micotoxinas, levando animais ou até mesmo seres humanos a desenvolver patologias crônicas ou toxicoses difusas (Calvo, 2005).

A diversidade de doenças de animais e humanas atribuídas às micotoxinas são devidas ao seu tamanho relativamente pequeno e à grande variedade de suas estruturas químicas, sendo que os sintomas das micotoxicoses são resultados de interações das micotoxinas com moléculas funcionais e organelas da célula animal (Oga, 1996; Songsermsakul \& Razzazi Fazeli, 2008)

Como nem todas as linhagens entre os fungos micotoxigênicos são produtoras de toxinas torna-se necessário a aplicação de métodos que propiciem a rápida e fácil identificação das mesmas (Saito \& Machida, 1999). No entanto, as micotoxinas ocorrem e exercem seus efeitos em quantidades extremamente pequenas nos alimentos, o que requer geralmente uma amostragem, preparação de amostras, extração e técnicas de análise sofisticadas para a identificação e avaliação quantitativa da toxicidade (FAO, 2001).

Apesar de serem oficialmente aceitas e validadas, as técnicas analíticas CLAE e GC demandam altos custos de instrumentação e manutenção, que restringem o seu uso (Sydenham \& Shephard, 1996). As propriedades cromatográficas das amostras podem ainda apresentar aspectos visíveis semelhantes o que pode comprometer a interpretação dos resultados obtidos (Valenta, 1998). Dessa forma, o ensaio imunoquímico é considerado a técnica analítica alternativa na análise de micotoxinas em alimentos (Xiulan et al., 2005; Kolosova et al., 2006).

As análises quantitativas e qualitativas de toxinas produzidas por fungos podem ser realizadas por cromatografia em camada delgada (CCD), cromatografia líquida de alta eficiência (CLAE), cromatografia gasosa-espectrometria de massa (GC- 
MS), cromatografia líquida-espectrometria de massa (LC-MS), cromatografia gasosa-espectroscopia infravemelho (GC-IV), imunoensaios pelo método ELISA (Enzyme Linked Immunosorbent Assay), aglutinação de látex (RPLA), imunodifusão, imunoafinidade, biosensores separação imunomagnética e imunohistoquímica (Pallaroni \& Von Holst, 2003; Pettersson; 2003; Van Der Gaag, et al., 2003; Soleas et al., 2001; Scott \& Trucksess, 1997; Pestka et al., 1994).

Outros tipos de técnicas de deteçãa de micotoxinas, como aplicação de biosensores de ressonância plásmica de superfície, eletrocinética capilar, transdução eletroquímica e monitoramento de injeção de fluxo, vêm sendo desenvolvidos no intuito de simplificar, acelerar e minimizar o custo das análises (Garden \& Strachan, 2001; Ammida et al., 2004; Kolosova et al., 2006).

Apesar de mais de quatro décadas de descoberta das micotoxinas, nenhum método de prevenção e controle mostrou-se seguro, eficaz e definitivo (Prado et al., 2006). Atualmente, o monitoramento da qualidade dos alimentos e procedimentos reguladores é o método utilizado para o controle de micotoxinas, sendo que inúmeros países já estabeleceram limites máximos de contaminação em alimentos e rações animais, principalmente para as aflatoxinas (Teixeira et al., 2008).

\subsection{Cromatografia acoplada à espectrometria de massas na determinação de substâncias tóxicas em alimentos}

Substâncias tóxicas são aquelas que impactam negativamente o metabolismo normal dos seres vivos, podendo levar ao estabelecimento de anormalidades fisiológicas e/ou anatômicas (Veja, 2000).

A presença de substâncias tóxicas em alimentos pode ser ocasionada por diversas fontes de contaminação. Uma das principais fontes de contaminação de alimentos é a utilização de agroquímicos, que são substâncias empregadas para aumentar a qualidade e a quantidade de alimentos necessários ao sustento da população (Veja, 2000).

Dentre os agroquímicos utilizados estão os agrotóxicos (herbicidas, inseticidas, fungicidas, acaricidas, fumigantes), que são aplicados a frutas e vegetais em vários estágios de cultivo e pós-colheita, para protegê-los do ataque de pestes e mantêlos próprios para o consumo (Lehotay, 2006). Outro tipo de agroquímico empregado, que pode gerar contaminação de alimentos de origem animal (carne, leite e ovos), são os medicamentos veterinários (Lehotay, 2006).

Além da contaminação por agroquímicos os alimentos também podem ser contaminados por toxinas geradas por microorganismos, como bactérias ou fungos (micotoxinas), por compostos tóxicos produzidos durante o preparo dos alimentos (acrilamidas, aminas heterocíclicas), por compostos presentes na composição de embalagens (estirenos, ftalatos), ou ainda por exposição dos alimentos a contaminantes ambientais (hidrocarbonetos polialogenados, hidrocarbonetos policíclicos aromáticos, organometálicos (Núñez, 2005). Existem poucos trabalhos na literatura relatando estes dois últimos tipos de contaminação (Sorensen, 2006).

Segundo Taylor et. al para garantir a segurança da população quanto ao consumo de alimentos, agências governamentais no mundo todo realizam um controle da presença dos contaminantes nos alimentos para que não gerem danos à saúde dos consumidores estabelecendo, para tanto, os limites máximos de resíduos ("maximun residue levels") - LMR. Para garantir que os LMR sejam respeitados, as metodologias analíticas utilizadas para a determinação de substâncias tóxicas em alimentos devem ser capazes de quantificar resíduos dessas substâncias em concentrações muito baixas, assim como identificálos de maneira inequívoca.

Segundo Lehotay et al., 2002, devido à complexidade das matrizes de alimentos (mistura de água, proteínas, lipídios, carboidratos, vitaminas e minerais), freqüentemente é necessária uma preparação intensiva da amostra, como também o acoplamento de técnicas analíticas para obtenção de maior seletividade e detectabilidade (Núñez, 2005).

Neste sentido, mostra-se vantajoso o emprego da cromatografia com detecção por espectrometria de massas acoplada a espectrometria de massas, uma vez que por EM-EM é possível obter uma grande quantidade de informação estrutural acerca 
do analito, o que assegura sua identificação com maior exatidão do que quando ela é feita apenas com base nas características de retenção dos compostos analisados, como ocorre nas outras técnicas de detecção cromatográficas (Vékey, 2001).

Além disso, quando existem compostos que não podem ser totalmente separados pela técnica cromatográfica empregada, usando EM-EM é possível detectá-los individualmente se possuírem diferentes massas molares ou gerarem diferentes espectros de massas (Vékey, 2001). Graças a essa elevada seletividade, os efeitos da interferência de componentes da matriz sobre o sinal obtido são minimizados, de forma que procedimentos mais simples de preparo das amostras podem ser empregados, eliminando, muitas vezes, a necessidade de realizar várias etapas de limpeza da amostra.

Segundo Vidal e Arrebola, isto diminui o custo e o tempo necessários para a realização das análises, de forma que possam ser aplicadas como procedimentos de rotina em laboratórios de controle da qualidade de alimentos. Quando se utiliza a EM-EM é possível obter maior detectabilidade e menores limites de detecção e quantificação do que quando se utiliza EM, devido aos modos de varreduras possíveis de serem realizados, o que favorece a sua aplicação à análise de traços (Vidal, 2002).

\subsection{Aplicação de CG-EM-EM e CL-EM-EM na determinação de agrotóxicos em alimentos}

Arrebola et al. desenvolveram um método para determinação de resíduos de agrotóxicos de 81 classes diferentes em vegetais frescos com grande conteúdo de água, como pepino, utilizando CG-EM-EM. Os agrotóxicos analisados foram: acefato, acrinatrina, azoxistrobina, betalaxil, bifentrina, bromopropilato, bupirimato, buprofezina, carbofenotiom, cialotrim, ciflutrina, cipermetrina, ciproconazol, clorfenvinfós, cloropirifós, cloropirifós metílico, clortalonil, clozolinato, deltametrina, diazinona, diclorvós, dicofol, difenoconazol, dimetoato, dissulfotom, $\alpha$-endossulfam, $\beta$-endossulfam, endossulfam sulfato, esfenvalerato, etiofencarbe, etiona, etoprofós, etrinfós, fenamifós, fenarimol, fenitrotiona, fenpropatrina, fentiona, flucitrinato, fludioxinil, forato, formotiom, fosalona, furatiocarbe, heptenofós, hexaconazol, iprodiona, isofenfós, lindano, malationa, metalaxil, metamidofós, mevinfós, miclobutanil, nuarimol, ometoato, oxadixil, parationa metílico, penconazol, pendimetalina, permetrina, pirazofós, piridabem, pirifenox, pirimetanil, pirimicarbe, pirimifós metílico, piriproxifem, procimidona, propargito, propiconazol, propoxur, quinometionato, tebuconazol, tebufenozide, tetraconazol, tetradifona, triadimefom, triadimenol, triflumizol e vinclozolina.

Para a extração dos agrotóxicos das matrizes de interesse foi utilizado apenas diclorometano e para eliminar a água, sulfato de sódio anidro. O extrato obtido foi redissolvido em cicloexano, seguido pela adição de padrão interno (cafeína) e injetado diretamente no cromatógrafo. Isto só foi possível devido à utilização de um filtro de carbono na linha de gás, posicionado antes da coluna, pois este reduz a entrada, nos instrumentos, de substâncias de baixa volatilidade e de interferentes, levando a um aumento da seletividade do sinal na EM-EM e evitando que houvesse a necessidade de realizar etapas de "clean-up" no procedimento de extração (Arrebola, 2003).

Para detecção foi utilizado um "ion-trap no modo EM-EM, empregando-se a IE. Quando se utiliza o "ion-trap", a detectabilidade é maximizada pela otimização da quantidade de íons aprisionados no "trap" e dos parâmetros envolvidos na dissociação dos íons precursores com um gás inerte (He) por DIC para obtenção de íons ou clusters de íons com grande abundância relativa no espectro, os quais são empregados na quantificação e identificação dos analitos.

Assim, quando se faz a análise de diferentes compostos utilizando EM-EM, vários parâmetros têm que ser otimizados para cada um deles, como amplitude de excitação, nível de excitação para armazenamento, quais íons serão selecionados para quantificação e a partir de qual íon precursor eles serão gerados e as janelas de tempo de retenção (JTR). Neste trabalho a JTR foi definida como o tempo de retenção médio mais ou menos três vezes a estimativa do desvio padrão dos tempos de retenção 
de 10 amostras não contaminadas, fortificadas a um nível médio com padrões de calibração de cada composto (Arrebola, 2003).

\subsection{Aplicação da CL-EM-EM à determinação de medicamentos veterinários em alimentos}

Fagerquist et al. realizaram a determinação quantitativa e qualitativa de antibióticos (em específico as $\beta$-lactamas: amoxilina, ampicilina, cefazolina, cloxacilina (clox), deacetil-cefapirim, desfuroilseftiofur cisteína dissulfeto (dcd), dicloxacilina (diclox), naficilina, oxacilina (ox) e penicilina G (pen G)) em carne bovina proveniente do Serviço de Segurança e Inspeção de Alimentos dos Estados Unidos da América (EUA), utilizando a extração em fase sólida e CL-EM-EM. No sistema cromatográfico foi utilizada uma vazão de $0,3 \mathrm{~mL} \mathrm{min-1}$ para gerar uma linha de base estável e uma ionização eficiente dos analitos por IEN. A análise por EM-EM foi realizada utilizando um triplo quadrupolo ajustado ao modo de varredura MRM, para monitorar as 4 transições mais abundantes do íon precursor - íon produto de cada analito.

O método desenvolvido foi comparado ao ensaio microbiológico utilizado pelo Serviço de Segurança e Inspeção de Alimentos dos EUA para determinação destas drogas veterinárias em carne. O método utilizando CL-EM-EM foi capaz de detectar antibióticos em níveis de concentração mais baixos que o ensaio microbiológico e também foi capaz de determinar a identidade de cada antibiótico presente, o que não foi possível no ensaio microbiológico. Com este método, também foi possível determinar quantitativamente os antibióticos abaixo dos níveis de tolerância estabelecidos por lei (Fagerquist, 2005).

Outro método de determinação de $\beta$-lactamas (amoxilina e ampicilina) em leite e carne bovina foi descrito por Bogialli et al., no qual foi adicionado às amostras um padrão interno (penicilina V) e, posteriormente, realizada a extração por dispersão da matriz em fase sólida com eluição utilizando água aquecida. Depois de ajustado o pH do extrato, este foi filtrado e analisado por CL-EM-EM utilizando coluna de fase reversa C18 no sistema cromatográfico, IEN e varredura MSR.

Os autores observaram um entupimento parcial da coluna de guarda C18 utilizada no sistema cromatográfico, o que foi atribuído à presença de sais insolúveis em água nos produtos de extração do fígado e dos rins bovinos. Mesmo assim o método apresentou boa precisão, exatidão e LD $<1 \mu \mathrm{g} \mathrm{kg-1}$ para ambos os analitos nas matrizes avaliadas (Bogialli, 2004).

Matabudul et al.desenvolveram um método para a determinação simultânea de antibióticos ionóforos (lasalocide, monensina, narasina e solinomina) em fígado de animais de diferentes espécies e em leite, previamente extraídos com acetonitrila e por EFS utilizando cartuchos de sílica e analisados por CL-EM-EM utilizando IEN no modo positivo e varredura MRM. Os antibióticos ionóforos complexam com cátions ( $\mathrm{K}+, \mathrm{Na}+, \mathrm{Ca} 2+$ e $\mathrm{Mg} 2+)$ e são lipossolúveis.

A voltagem da IEN para obtenção de íons produto $[\mathrm{M}+\mathrm{Na}]+$ foi ajustada utilizando soluções de padrões dos agrotóxicos dissolvidos na FM (acetonitrila, metanol, tetraidrofurano, água e ácido trifluoracético 67:10:10:13:0,1 v/v). Não foram observados interferentes nos espectros e recuperações semelhantes foram obtidas para as diferentes matrizes, de forma que foi possível considerar o método desenvolvido robusto e versátil. Como o tempo de preparo das amostras neste método foi menor que $3 \mathrm{~h}$, ele pode ser empregado na análise de mais de 40 amostras por dia (Matabudul et al., 2001).

Andersen et al. desenvolveram um método para determinação de algumas tetraciclinas, antibióticos veterinários também utilizados em aquacultura, em amostras de camarão e leite integral usando CLAE, com detecção por ultravioleta e a confirmação do resíduo por EM e EM-EM. As amostras de leite e camarão foram extraídas adicionando-se ácido succínico e, em seguida, foi realizada uma etapa de limpeza por EFS. O espectrômetro de massas, um triplo quadrupolo usando IEN no modo positivo, foi ajustado para realizar a varredura no modo MSR, de maneira que foi possível confirmar a presença do resíduo de três tetraciclinas (tetraciclina, oxitetracilina e clorotetraciclina) em concentrações entre 25 e 400 ng g-1.

Nicolich et al. desenvolveram um método para determinação de cloranfenicol em leite por LC-EM-EM no modo MRM, com IEN e utilizando padrão interno marcado isotopicamente (deuterado- D5). O cloranfenicol é um antibiótico de 
largo espectro que é capaz de causar doenças sanguíneas fatais em seres humanos. Além disso, não é possível estabelecer um limite para a presença de seus resíduos e de seus metabólitos nos alimentos que garantam a segurança dos consumidores, ou seja, o LMR do cloranfenicol não pode ser determinado. Desta maneira, o uso do cloranfenicol em animais geradores de alimentos é proibido em diversos países, inclusive no Brasil.

As amostras de leite foram fortificadas com o padrão interno e submetidas à extração líquido-líquido com acetato de etila e uma solução de ácido fórmico (10 mmol L-1). A separação cromatográfica foi realizada empregando-se uma coluna cromatográfica Varian Pursuit em combinação com uma coluna de guarda Varian MetaGuard e, como FM, foram utilizadas soluções de $0,1 \%$ de ácido fórmico em água e $0,1 \%$ de ácido fórmico em acetonitrila. A curva analítica foi obtida utilizando-se o branco da matriz fortificado com soluções de padrão de cloranfenicol. O método desenvolvido apresentou limite de decisão de $0,05 \mathrm{ng} \mathrm{mL}^{-1}$ e capacidade de detecção de $0,09 \mathrm{ng} \mathrm{mL}^{-1}$, os quais foram calculados a partir das curvas analíticas, assim como boa exatidão e precisão, de forma que este método pode ser aplicado no monitoramento do cloranfenicol em amostras de leite obtidas em supermercados brasileiros (Nicolich et al. 2006).

Mottier et al. realizaram a determinação quantitativa de quatro metabólitos de nitrofurano (furaltadona, furazolidona, nitrofurantoína e nitrofurazona) em carne por CL-EM-EM com IEN, utilizando padrões internos marcados isotopicamente. Os nitrofuranos são utilizados como aditivos em ração animal para o tratamento profilático e terapêutico de doenças causadas por bactérias e protozoários e alguns deles foram proibidos na Europa por serem mutagênicos e carcinogênicos. As amostras foram primeiramente extraídas com acetato de etila e, em seguida, foram submetidas a uma etapa de limpeza por EFS para posterior injeção no sistema CLAE, no qual foi utilizado gradiente linear para eluição dos analitos em fase reversa.

Heller et al. realizaram a quantificação de resíduos de sulfonamidas (sulfacetamida, sulfacloropiridazina, sulfadiazina, sulfadimetoxalina, sulfadimetoxina, sulfagüanidina, sulfamerazina, sulfametazina, sulfametiazol, sulfametoxazol, sulfametoxipiridazina, sulfamonometoxina, sulfanilamida, sulfapiridina, sulfatiazol e sulfisoxazol) em ovos por CLAE com detecção ultravioleta e confirmação por EM-EM.

As amostras foram extraídas com acetonitrila, seguida de uma etapa de limpeza por EFS utilizando um cartucho de C18. Os analitos foram separados por CLAE em fase reversa (coluna C18) utilizando eluição por gradiente, ionização por IEN e detecção por EM-EM em um espectrômetro de massas "ion-trap". Os íons moleculares protonados foram isolados e dissociados para obtenção do espectro de massas a partir da varredura de todos os íons produtos (Heller, 2002).

A análise de quatro 5-nitroimidazóis (dimetridazol, ipronidazol, metronidazol e ronidazol) e seus correspondentes metabólitos hidroxilados em ovos, ovos processados e carne de frango foi realizada por Mottier et al. utilizando CL-EM-EM e padrões internos marcados isotopicamente. Os 5-nitromidazóis são antibióticos de uso veterinário suspeitos de serem carcinogênicos e mutagênicos em seres humanos. Estes compostos são metabolizados rapidamente e alguns de seus metabólitos são carcinogênicos e mutagênicos em certas espécies de animais, daí a importância de se monitorar não só os antibióticos, mas também seus metabólitos.

As amostras de ovos foram fortificadas com padrões internos dos analitos deuterados e depois submetidas à extração com acetonitrila e posterior etapa de limpeza por EFS. As amostras de carne foram também fortificadas com os padrões internos deuterados, mas foram extraídas com acetato de etila e apenas filtradas após a extração, antes de serem injetadas no cromatógrafo. No sistema cromatográfico foi utilizada a eluição por gradiente linear em fase reversa para separar os analitos. O espectrômetro de massas, um triplo quadrupolo, foi ajustado ao modo MRM para o monitoramento de duas transições para cada 5-nitroimidazol e seus correspondentes padrões internos. Os analitos foram ionizados por IEN no modo positivo (Mottier, 2006). 


\subsection{Aplicação de CL-EM-EM e CG-EM-EM na determinação de toxinas em alimentos}

Chen et al. desenvolveram um método para determinação de aflatoxinas em leite líquido e em pó, utilizando EFS com alta vazão e CL-EM-EM. As aflatoxinas são metabólitos secundários da Aspergillus flavuse, Aspergillus parasiticus, sendo encontradas frequientemente em cereais contaminados e frutas secas. A aflatoxina B1 (AFB1) é a que possui maior toxicidade, uma vez que pode causar câncer de fígado quando um indivíduo é exposto por longo tempo a esta toxina, principalmente quando se tratam de pessoas com hepatite B. O principal metabólito da AFB1 é a aflatoxina M1 (AFM1), que é menos carcinogênica que AFB1 e pode ser encontrada na urina, sangue, leite e órgãos internos de animais infectados.

O desenvolvimento de uma metodologia para determinação de azaspiracide em mariscos por CL-EM-EM foi realizado por Draisci et al. A azaspiracide é uma toxina responsável por casos de intoxicação de seres humanos resultante do consumo de mariscos na Europa. Este analito foi extraído de mexilhão utilizando acetona e, a seguir, foi submetido à análise cromatográfica usando uma microcoluna C18 (fase reversa) e eluição isocrática, a uma vazão de $30 \mu \mathrm{L}$ min-1, com acetonitrila:água $(85: 15 \mathrm{v} / \mathrm{v})$ contendo $0,03 \%$ de ácido trifluoracético. A toxina foi ionizada numa interface IEN operando no modo positivo, sendo gerada somente, como íon precursor, a molécula protonada. Por DIC, em um triplo quadruplo, o íon precursor foi dissociado em três íons produto, $[\mathrm{M}+\mathrm{H}-\mathrm{nH} 2 \mathrm{O}]+\mathrm{com} \mathrm{n}=1-3$, os quais foram identificados utilizando MSR. Com o método desenvolvido foi possível obter boa linearidade no intervalo de concentração entre $0,1 \mathrm{e} 1 \mu \mathrm{g}$ mL-1 (padronização externa) e LQ instrumental consideravelmente menor que o limite obtido em ensaios biológicos.

Rundberget e Wilkins realizaram a determinação de micotoxinas do Penicillium (ácido micofenolítico, chaetoglobosina B, griseofulvina, penitrem A, roquefortine C e verruculogena) em alimentos utilizando LC-MS-MS. Os autores ressaltaram que, devido à grande toxicidade das micotoxinas do Penicillinum, há a necessidade do uso de técnicas de análise com as quais se consiga atingir baixos limites de detecção.

Lau et al. desenvolveram um procedimento para a determinação de micotoxinas da Alternaria (alternariol e monometil éter alternariol) em sucos de frutas e bebidas alcoólicas por CLAE-UV, CL-EM e CL-EM-EM. Estas micotoxinas são apontadas como possíveis causadoras de câncer no esôfago de seres humanos.

Outro trabalho de determinação de micotoxinas em alimentos foi realizado por HAUBL et al., que utilizaram CL-EMEM para determinação de dioxinivalenol em milho, empregando um padrão interno marcado isotopicamente ( $\left.{ }^{13} \mathrm{C}\right)$.

\subsection{Aplicação de CG-EM-EM e CL-EM-EM à determinação de substâncias tóxicas geradas durante o preparo dos alimentos}

Hoenicke et al. realizaram a análise de acrilamida em diferentes tipos de alimentos utilizando CL-EM-EM e CG-EMEM. Atribui-se a presença de acrilamida em alimentos à reação de Maillard, que é responsável pelos sabores e coloração "marrom" característicos de alimentos fritos e assados. Segundo os autores, o monitoramento da presença de acrilamida em alimentos se faz necessária por ser considerada um composto potencialmente carcinogênico. Nesse trabalho foram utilizadas duas técnicas de extração, sendo que uma delas foi realizada com iso-hexano, seguida por uma etapa de purificação com hexacianoferrato de potássio e sulfato de zinco (precipitação de Carrez).

$\mathrm{Na}$ outra técnica, a extração foi feita com água em banho de ultra-som, seguida de purificação empregando a precipitação de Carrez e uma etapa de extração com acetato de etila. Segundo os autores, o uso da precipitação de Carrez para purificação da amostra permitiu que mais de 60 amostras fossem preparadas por dia. Porém, esta etapa foi insuficiente para purificar amostras de matrizes muito complexas, como café solúvel e cacau, daí a necessidade de se realizar uma etapa "extra" de extração. Esta etapa adicional foi capaz de eliminar as interferências espectrais. 
A análise por CL-EM-EM foi realizada utilizando IEN no modo positivo e um triplo quadrupolo ajustado para obtenção dos espectros por MRM. No sistema cromatográfico foi empregada eluição por gradiente utilizando como fase móvel uma mistura de acetonitrila: ácido acético $1 \%$ em fase reversa (coluna LiChrospher $100 \mathrm{CN}$ ), numa vazão de $0,7 \mathrm{~mL}$ min-1 ${ }^{1}$ No sistema CG-EM-EM o cromatógrafo a gás foi acoplado a um triplo quadrupolo, sendo utilizada a IQ para ionização do analito no modo positivo e MSR para obtenção dos espectros de massas. Com CL-EM-EM foi possível obter um LD de $10 \mu$ g kg- ${ }^{1}$ e com CG-EM-EM, o LD foi de $5 \mu \mathrm{g} \mathrm{kg-1}$ (Hoenicke, 2004).

Outro trabalho visando a determinação de acrilamida em alimentos por CL-EM-EM foi realizado por Bermudo et al. Para isso foi empregado um espectrômetro "ion-trap" e a ionização do analito foi realizada no modo positivo por IQPA. No sistema cromatográfico foi utilizada fase reversa e uma FM com $100 \%$ de água, a uma vazão de 0,3 mL min-1 . Antes da etapa de extração foi adicionado às amostras um padrão interno de acrilamida marcada isotopicamente para posterior quantificação. A extração foi feita com água, por agitação e, em seguida, a limpeza foi realizada por EFS.

O método desenvolvido por Bermudo et al. foi aplicado a 30 amostras de alimentos coletadas em supermercados de Barcelona e quando a acrilamida estava presente nas amostras em concentrações inferiores ao LD de 45 ng g-1, obtido utilizando o "ion-trap", empregava-se um triplo quadrupolo ajustado ao modo de varredura MRM para efetuar a determinação. Os maiores teores de acrilamida foram encontrados em batatas fritas (500 a $9250 \mathrm{ng} \mathrm{g}^{1}{ }^{1}$ ).

Zhang et al. determinaram acrilamida em alimentos infantis à base de cereais por CL-EM-EM, empregando, para isto, um triplo quadrupolo e ionização por IEN no modo positivo. A gordura presente nas matrizes analisadas foi extraída com éter de petróleo e, em seguida, a extração foi realizada com uma solução aquosa de cloreto de sódio (2 mol L-1) e acetato de etila. A etapa de limpeza do extrato foi realizada por EFS. Antes de serem submetidas à extração, as amostras receberam a adição de um padrão interno de acrilamida marcada isotopicamente, com o objetivo de verificar a ocorrência de perdas durante o prétratamento da amostra e também para seu emprego na quantificação, uma vez que as curvas analíticas foram obtidas pela razão entre a área do pico cromatográfico da acrilamida não marcada e a marcada presente nos padrões utilizados. Após a validação, os autores concluíram que o método desenvolvido é seletivo, preciso e robusto e pode ser empregado na determinação de acrilamida em baixos níveis de concentração em alimentos (LQ de $3 \mu \mathrm{g} \mathrm{kg-1)}$ ).

Andrzejwski et al. otimizaram um método para determinação de acrilamida em café solúvel, pronto e em grãos por CL-EMEM. Foi adicionado padrão interno marcado isotopicamente $\left({ }^{13} \mathrm{C}\right)$ às amostras para sua posterior extração com água, seguida de uma etapa de limpeza por EFS, com colunas Oasis HBL. A análise por CL-EM-EM foi realizada em fase reversa no sistema cromatográfico, empregando-se uma coluna Synergi Hydro-RP, com partículas de $4 \mu$ m. Foi usada eluição isocrática, com fase móvel de $0,5 \%$ de metanol em água, acoplado a um triplo quadrupolo com ionização por IEN e varredura MRM.

Graças ao emprego de um padrão interno estável, os autores puderam observar a perda do sinal da acrilamida após sucessivas injeções do extrato de café. Este problema pôde ser solucionado ajustando-se a temperatura da coluna. Foi também observada a presença de interferentes co-extraídos nos cromatogramas obtidos, porém, estes sinais não interferiram no sinal da acrilamida ou do padrão interno graças à boa resolução cromatográfica obtida. O método desenvolvido apresentou boa linearidade e possibilitou verificar a presença de acrilamida em diversas marcas populares de café (Zhang, 2005).

\section{Considerações Finais}

O uso da cromatografia abrange muitas áreas do conhecimento, e suas funcionalidades são inumeráveis. Os trabalhos envolvendo essas técnicas multiplicam-se dia a dia, o que torna difícil acompanhar sua evolução nas diferentes áreas.

$\mathrm{Na}$ medicina veterinária, apesar do uso estar relatado em diferentes áreas, seu emprego está restrito à área toxicológica e na detecção de contaminantes de alimentos de origem animal. Mesmo na área toxicológica a quantidade de trabalhos que 
utilizam diretamente a cromatografia é restrita, sendo que grande parte destes utiliza-a de forma isolada, e descrevendo como o método cromatográfico foi utilizado, o que muitas vezes torna difícil a reprodutibilidade da metodologia.

Apesar da grande utilidade da cromatografia, os equipamentos empregados nas técnicas mais modernas têm alto custo e demanda de pessoal especializado para operá-los. Assim o uso dessas técnicas fica restrito, e muitas vezes há a impossibilidade de realizá-las, e por vezes, diagnósticos toxicológicos não podem ser estabelecidos com precisão.

As técnicas cromatográficas mais comumente acopladas à espectrometria de massas são a cromatografia gasosa e a cromatografia líquida de alta eficiência. A combinação com outras técnicas de separação, como a eletroforese capilar, a cromatografia em camada delgada e a cromatografia de permeação em gel é possível, mas usada com menor frequência.

Debates em andamento na área de segurança alimentar, sugerem para o futuro próximo, a adoção da espectrometria de massas de alta resolução como padrão para a geração de dados por laboratórios acreditados, credenciados e recomendados por ela nessa área.

\section{Referências}

ANVISA. (2006). Programa de Análise de Resíduos de Medicamentos Veterinários em Alimentos de Origem Animal - PAMVET. Relatório 2004/2005 Monitoramento de Resíduos em Leite Exposto ao Consumo, Ministério da Saúde, 46 p.

ANVISA. (2009). Programa de Análise de Resíduos de Medicamentos Veterinários em Alimentos de Origem Animal. PAMVET. RELATÓRIO 2006/2007 Monitoramento de Resíduos em Leite Exposto ao Consumo, Ministério da Saúde, 76 p.

Ammida, N. H. S., Micheli, L., \& Palleschi, G. (2004). Electrochemical immunosensor for determination of aflatoxin B1 in barley. Analytica Chimica Acta, $520,159-164$.

Amorim, R., Galhardo, A., Valadão, C. A. A., \& Peccinini, R. G. (2008). Determinação de cetamina em plasma por HPLC: aplicação em um estudo de farmacocinética de associação medicamentosa em cães. Revista de Ciências Farmacêuticas Básica e Aplicada, Araraquara, 29(1):69-75.

Ardrey, R. E. et al (2003). Liquid Chromatography-Mass Spectrometry: An Introdution, Wiley: Huddersfield, 296 p.

Barbosa, J. D., Oliveira, C. M. C., Tokarnia, C. H., \& Riet-Correa, F. (2003). Comparação da sensibilidade de bovinos e búfalos à intoxicação por Palicourea marcgravii (Rubiaceae). Pesquisa Veterinária Brasileira, 23(4):167-172.

Batemanm, K., Castro-Perez, J., Wrona, M., Shockor, J. P., Yu, K., Oballa, R. et al. (2007). MSE with mass defect filtering for in vitro and in vivo metabolite identification. Rapid Communications in Mass Spectrometry.

Bok, J. W., Keller, N. P., \& Lae, A. (2004). A regulator of secondary metabolism in Aspergillus spp. Eukaryotic Cell, 3, $527-535$.

Bruno, R. L. A. (2000). Qualidade fisiológica e microflora de sementes de amendoim cv. Br- 1 durante o armazenamento. Revista de Oleaginosa e Fibrosa, Campina Grande, 4 (3):141-152.

Calvo, A. M. (2005). Mycotoxins. In: Dabrowski, W. A., Sikorski, Z. E. Toxins in Food. London: CRC Press, 219-240.

Cardoso, O. M. C., Silva, T. J. P., Santos, W. L. M., \& Pesquero, J. L. (1999). Ocorrência de resíduos de dietilestilbestrol e zeranol em fígado de bovinos 26 abatidos no Brasil. Ciência e Tecnologia de Alimentos, 19, 3.

Chiaradia, M. C., Collins, C. H., \& Jardim, I C. S. F. (2008). O Estado da Arte da Cromatografia Associada à Espectrometria de Massas Acoplada à Espectrometria de Massas na Análise de Compostos Tóxicos em Alimentos. Química Nova, 31(3):623-636.

Chinchole, R., Hatre, P. M., Desai, U., \& Chavan, R. (2012). Recent applications of hyphenated liquid chromatography techniques in forensic toxicology: a review. International Journal of Pharmaceutical Sciences Review and Research, 14, 1.

Cunha, L. C., Pípole, F., Carvalho, L. R., Lago, J. H. G., \& Gorniak, S. L. (2012). Isolation and characterization of sodium 2-fluoroacetate from Mascagnia rigida using chromatography and infrared spectroscopy. Toxicon, 60, 329-332.

Degani, A. L., Case, Q. L., \& Viera, P. C. (1998). Cromatografia um breve ensaio. Química nova na escola, 7, 21-25.

Duarte, K. M. R., Silva, F. M. S. M., \& Meirelles, C. F. (2002). Resíduos de anabolizantes na produção animal: importância e métodos de detecção. Ciência Rural, 32(4):731-737.

FAO. (2001). Micotoxinas em grãos. Países Baixos: FAO, n. 3

Feltrin, C. W., Mello, A. M. S., Santos, J. G. R., Marques, M. V., Seibel, N. M., \& Fontoura, L. A. M. (2007). Quantificação de sulfadimetoxina em leite por cromatografia líquida de alta eficiência. Química Nova, 30(1):80-82.

Garden, S. R., \& Strachan, N. J. (2001). Novel colorimetric immunoassay for the detection of aflatoxin B1. Analytica Chimica Acta, Amsterdam, 444, 187191. 
Gentili, A., Caretti, F., Bellante, S., Rocca, L. M., Curini, R., \& Venditti, A. (2012). Development and validation of two multiresidue liquid chromatography tandem mass spectrometry methods based on a versatile extraction procedure for isolating non-steroidal anti-inflammatory drugs from bovine milk and muscle tissue. Analytical and Bioanalytical Chemistry, 404(5):1375 -1388.

Gilbert-López, B., Garcia-Reyes, J. F., \& Molina-Diaz, A. (2012). Determination of fungicide residues in baby food by liquid chromatography-ion trap tandem mass spectrometry. Food Chemistry, 135, 780-786.

Kaiser, A. M., Mcfarland, W., Siemion, R. S., \& Raisbeck, M. F. (2010). Secondary pentobarbital poisoning in two dogs: a cautionary tale. Journal of Veterinary Diagnostic Investigation, 22, 632-634.

Kennedy, D. G., Mccracken, R. J., Cannavan, A., \& Hewitt, S. A. (1998). Use of liquid chromatography-Mas spectrometry in the analysis of residues of antibiotics in meat and a milk. Journal of Chromatography, 812(1-2):77-98.

Kolosova, A.Y., Shim, W., Yang, Z., Eremin, S.A., \& Chung, D. (2006). Direct competitive ELISA based on a monoclonal antibody for detection of aflatoxin B1 - stabilization of ELISA kit components and application to grain samples. Analytical and Bioanalytical Chemistry, 384, 286-294.

Kukusamude, C., Burakham, R., Chailapakul, O., \& Srijaranai, S. (2012). High performance liquid chromatography for the simultaneous alalysis of penicillin residues in beef and milk using ion-paired extraction and binary water-acetonitrile mixture. Talanta, 92, 39-44.

Leeson, S., Diaz, G. J. \& Summers, J. D. (1995). Poultry Metabolic Disorders and Mytoxins. Guelph, Ontario: University Books, $249-280$.

Lee, S. T., Cook, D., Riet-Correa, F., Pfister, J. A., Anderson, W. R., Lima, F. G., \& Gardner, D. R. (2012). Detection of monofluoroacetate in Palicourea and Amorimia species. Toxicon, 60: 791-796.

Lehotay, S. J., Son, K. A., Kwon, H., Koesukwiwat, U., Fu, W., Mastovska, K., Hoh, E., \& Leepipatpiboon N. (2006). Comparison of QuEChERS sample preparation methods for the analysis of pesticide residues in fruits and vegetables. J. Chromatogr. A. 1217: 2548-2560.

Lobato, V., Rath, S., \& Reyes, F. G. R. (2006). Ocurrence of iverectin in bovine milk from the Brazilian retail market. Food Additives and Contaminants, 23(7):668-673.

Machinski Jr., M., \& Mídio, A. F. (1995). Patulina em alimentos - aspectos toxicológicos e analíticos. Revista de Farmácia e Bioquímica da Universidade de São Paulo, 31(1):1-19.

Manjarrez, J. L. A., Tellez, S. A., Martinez, R. R., \& Hernandez, V. O. F. (2012). Determination of rifaximin in milk of dairy cows using high pressure liquid chromatography (HPLC). Revista Científica, FCV-LUZ, 22(2):112-119.

Marriott, P. J., Haglund, P., \& Ong, R. C. Y. (2003). A review of environmental toxicant analysis by using multidimensional gas chromatography and comprehensive GC. Clinica Chimica Acta, 328: 1-19.

Mühlen, C. V., Zini, C. A., Caramão, E. B., \& Marriott, P. J. (2006). Caracterização de amostras petroquímicas e derivados utilizando cromatografia gasosa bidimensional abrangente (GCxGC). Química Nova, 29(4):765-775.

Netto, D. P., Zanluchi, A. R., Sassahara, M., \& Yanaka, E. K. (2002). Micotoxinas em alimentação animal no período de maio/1997 a março/2001 no Laboratório de Toxicologia Veterinária da Universidade Estadual de Londrina. Semina, 23(1):63-69.

Nunes, I. L., Magagnin, G., Bertolin, T. E., \& Furlong, E. B. (2003). Arroz comercializado na região sul do Brasil. Ciência e Tecnologia de Alimentos, 23(2):190-194.

Oga, S. (1996). Fundamentos de toxicologia. (2a ed.), Atheney, 515p.

Oliveira-Filho, J. C., Camo, P M. S., Iversen, A., Nielsen, K. F. \& Barros, C. S. L. (2012). Experimental poisoning by Baccharis megapotamica var. weirii in buffalo. Pesquisa Veterinária Brasileira, 32(5):383-390.

OMS. (1983). Critérios de salud amblental 11: Micotoxinas. O.P.S., Cidade do México. 131p.

Pallaroni, L., \& Von Holst, C. (2003). Determination of zearalenone from wheat and corn by pressurized liquid extraction and liquid chromatographyelectrospray mass spectrometry. Journal of Chromatography, 993(1-2):39-45.

Patel, K. M., Patel, J. K., Patel, M. P., Rajput, G. C., \& Patel, H. A. (2010). Introduction to hyphenated techniques and their application in pharmacy. Pharmaceutical Methods, 1,1 .

Pereira, M. M. G., Carvalho, E. P., Pedro, G., Rosa, C. A. R., Veloso, T., Souza, L. A. F., \& Ribeiro, J. M. M. (2005). Aflatoxinas em alimentos destinados a bovinos e em amostras de leite da região de Lavras, Minas Gerais - Brasil. Ciência e Tecnologia de Alimentos, Campinas, 29(1):106-122.

Peres, T. B. (2002). Noções básicas de cromatografia. Biológico, 64(2):227-229.

Pestka, J. J., Azcona-Oliveira, J. I., Plattner, R. D., Minervini, F., Doko, M. B., \& Visconti, A. (1994). Comparative assessment of fumonisin in grain based foods by ELISA, GC-MS, and HPLC. Journal of Food Protection, 57(2):169- 172.

Pettersson, H., \& Aberg, L. (2003). Near infrared spectroscopy for determination of mycotoxins in cereals. Food Control, 14(4):229-232.

Pietrón, W., Cybulski, W., Kos, K., \& Mitura, A. (2011). Analytical procedure for the determination of tylosin a in feedingstuff by liquid chromatographyultraviolet detection. The Bulletin of Veterinary Institute in Pulawy, 55:725-729. 
Pitt, J. I., \& Hocking, A. D. (1986). Mycotoxins in foods: implications for human health. In: Wahlqvist, M. L., Truswell, A. S. (Ed.). Recent advances in clinical nutrition. London: John Libby, 161-168.

Pozzi, C. R., Arcaro, J. R. P., Arcaro Júnior, I., Fagundes, H., \& Corrêa, B. (2002). Aspectos relacionados à ocorrência e mecanismo de ação de fumonisinas. Ciencia Rural, 32(5):901-907.

Prado, G., Carvalho, E.P., Madeira, J. E. G., Morais, A.D., Oliveira, M. S., Corrêa, R. F., \& Cardoso, V. N. (2006). Efeito da irradiação (60C ${ }^{\circ}$ ) na frequência fúngica de amendoim in natura em função do tempo de prateleira. Ciência e Agrotecnologia, 30(5):930-936.

Sabino, M., Prado, G., Inomata, E. I., et aI. (1988). Ocorrência natural de aflatoxinas e zearalenona em milho no Brasil -11 parte. In: Encontro Nacional de Micotoxinas, 5. São Paulo, SP. 16-18 maio, 1988 a. Resumos... São Paulo, Instituto Adolfo Lutz, 21p.

Saito, M., \& Machida, S. (1999). A rapid identification method for aflatoxin-producing strains of Aspergillus flavus and A. parasiticus by ammonia vapor. Mycoscience, 40;205-208.

Sanches, S. M., Da Silva, C. H. T. P., Campos, S. X., \& Vieira, E. M. (2003). Pesticidas e seus respectivos riscos associados à contaminação da água. Pesticidas: Revista Ecotoxicologia e Meio Ambiente, 13:53-58.

Scott, P. M., \& Trucksess M. W. (1997). Application of Immunoaffinity Columns to Mycotoxin Analysis. Journal of AOAC International, 80(5):941- 949.

Soleas, G. J., Yan, J., \& Goldberg, D. M. (2001). Assay of ochratoxin A in wine and beer by high pressure liquid chromatography photodiode array and gas chromatography mass selective detection. Journal of Agricultural and Food Chemistry, 49(6):2733-2740.

Songsermsakul, P., \& Razzazi-Fazeli, E. (2008). A Review of Recent Trends in Applications of Liquid Chromatography-Mass Spectrometry for Detection of Mycotoxins. Journal of Liquid Chromatography \& Related Technologies, 31:1641-1686.

Souza, S. V. C., Silva, G., Diniz, M. H. G. M., Santos, E. V., Lima, J. A., \& Teodoro, J. C. (2003). Determinação de resíduos de avermectinas em fígado bovino por cromatografia líquida de alta eficiência. Ciência e Tecnologia de Alimentos, 23(1):54-58.

Sydenham, E.W., \& Shephard, G.S. (1996). Chromatographic and allied methods of analysis for selected mycotoxins. In: GILBERT, J. Progress in Food Contaminants Analysis. London: Blackie Academic \& Professional, p.65-146.

Teixeira, A. S., Freitas-Silva, O., Godóy, R. L. O., Vargas, E. A., \& Martins, A. (2008). Análise e quantificação de aflatoxinas por cromatografia líquida de alta eficiência (CLAE) em amostras de castanha-do-Brasil. Revista Ciência da Vida, 28:22-24.

Valenta, H. (1998). Chromatographic methods for the determination of ochratoxin A in animal and human tissues and fluids. Journal of Chromatography A, $815: 75-92$.

Van Der Gaag B., Spath, S., Dietrich, H., Stigter, E., Boonzaaijer, G., Van Osenbruggen, T., \& Koopal, K. (2003). Biosensors and multiple mycotoxin analysis. Food Control, 14(4):251- 254.

Vanhaecke, L., Vanden Bussche, J., Wille, K., Bekaert, K., \& De Brabander, H. F. (2012). Ultra-high performance liquid chromatography-tandem mass spectrometry in high-throughput confirmation and quantification of 34 anabolic steroids in bovine muscle. Analytica Chimica Acta, $1(2): 70-77$.

Veja, P. V., \& Florentino, B. L. (2000). Toxicologia de Alimentos, Centro Nacional de Salud Ambiental: México, 2000.

Matínez Vidal, J. L. et al. (2006). Validation of a gas chromatography-triple quadrupole mass spectrometry based method for the quantification of pesticides in food commodities. Rapid Communications in Mass Spectrometry, 20:365- 375.

Xiulan, S., Xiaolan, Z., Jian, T., \& Chu, F. S. (2005). Preparation of gold-labeled antibody probe and its use in immunochromatography assay for detection of aflatoxin B1. International Journal of Food Microbiology, 99:185-194.

$\mathrm{Xu}, \mathrm{X}$. M., Yu, S., Li, R. et al. (2012). Distribution and migration study of pesticides between peel and pulp in grape by online gel permeation chromatography-gas chromatography/mass spectrometry. Food Chemistry, v. 135, p. 161 - 169.

Yu, J., Cleveland, T. E., Nierman, W. C., \& Bennett, J. W. (2005). Aspergillus flavus genomics: gateway to human and animal health, food safety, and crop resistance to diseases. Revista Iberoamericana de Micologia, 22:194-202.

Zhang, X. L., Zhao, T., Cheng, T., Liu, X. Y., \& Zhang, H. X. (2012). Rapid resolution liquid chromatography (RRLC) analysis of amino acids usingprcolumn derivatization. Journal of Chromatography B-Analytical Technologies in the Biomedical and Life Sciences, 906:91-95. 